\title{
Family-run lab raising the bar
}

If you want a dental lab that meets exceptional quality standards while still providing a personal service tailored to you, Knight Dental Design is here to help.

We are a family-run dental laboratory with a passion for delivering aesthetic technical solutions for private practices across the UK and Ireland. We pride ourselves on the personalised service we provide and will really go that extra mile to help your business thrive. We work closely with our partner practices to help them educate patients to the benefits of modern aesthetic dentistry. We provide substantial marketing support and our work is credited for the growth of many of our clients' practices.
To see how Knight Dental Design has raised the bar for cosmetic dental laboratories, visit www.knightdentaldesign. co.uk, email info@kdduk.net or call 0208 3170979 .
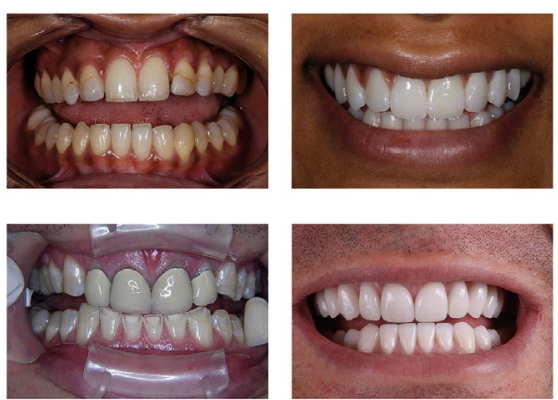

\section{Demand for confidence boosting dental treatments}

\section{prompts expansion plans}

Demand for treatments that provide more personal confidence has increased dramatically over the last six months as Brits eye a return to more in-person interaction as restrictions ease - and the exponential interest in better smiles is a clear indicator of this.

Following a time dominated by Zoom and other online meetings, PlusDent, a fast growing invisible teeth aligners company which works with GDC-registered dentists across the UK, has seen its number of UK patients almost double in the last six months and now plans to expand further in the UK as a result.

PlusDent works exclusively with dentists who monitor the patient's treatment from start to finish, with face-to-face interaction and physical assessments for initial consultation and therapy decision. So, unlike businesses offering direct-to-consumer only models and home kits, it matches guidance that the General Dental Council (GDC) announced regarding the importance of patients meeting with a dental professional before undergoing alignment treatment.

Using state-of-the-art invisible aligners, PlusDent ensures that everyone can have their teeth corrected by gentle pressure within a few months under General
Dental Council (GDC) registered dental supervision.

Key features of the PlusDent service:

$\rightarrow$ The consultation takes place and information on the service is shared on site in the dental practice; further communication and support with the dental team is all done via the app. In this way, PlusDent guarantees maximum flexibility with the best, continuous dental care

$\rightarrow$ The patient documents the progress of their treatment via the PlusDent app, and all check-ups are always validated by several dentists. With the data recorded in this way, a medical team can proceed much more precisely than with conventional therapy

$\rightarrow$ The app's transparency allows the patients to track every step of their treatment and see the progress of their treatment on a daily basis, which is incredibly motivating

$\rightarrow$ The treatment is safe, comfortable and, on average, $70 \%$ cheaper than conventional fixed braces as the process is completely digitised. The orthodontics are fully responsible for the treatment, and the aligners are produced in PlusDent's dental laboratory in Germany.

For more information visit https:// plusdent.co.uk/.

\section{Perfect clarity at} \section{first sight}

Benefit from perfect clarity at first sight with the EyeMag Pro dental loupes supplied by Nuview. These loupes provide high-contrast stereoscopic images with edge-to-edge sharpness, enabling you to visualise and differentiate minute details.

Available in various magnification

levels, EyeMag Pro loupes offer settings for a wide range of tilt and angle views, whilst facilitating a comfortable, ergonomic working position.

The EyeMag Pro can also be mounted on an adjustable headband or a lightweight titanium eyeglass frame, which can be fitted with prescription lenses at any time to further support the way you work.

To contact Nuview to arrange a fitting and for more information please call Nuview on 01453 872266, email info@ nuview-ltd.com, visit www.nuview.co or 'like' Nuview on Facebook.

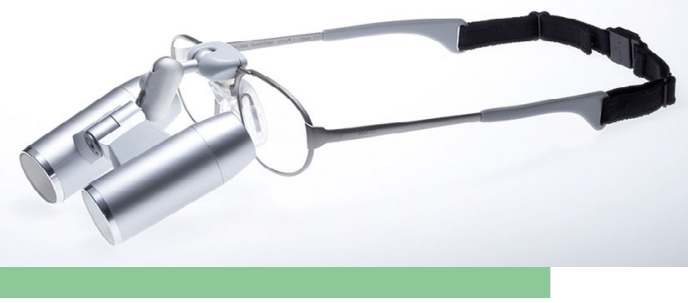

Supporting your financial goals

Whether you're looking to branch out and buy a new practice or are heading towards the end of your career and retirement, the award-winning team at money4dentists can help ensure your financial goals become a reality.

The team have routinely been voted the best financial advisers for dental professionals due to their wealth of knowledge and unique understanding of the industry.

So, if you need independent advice on pensions, insurance and more, be sure to contact money4dentists. Call 0845345 5060, email info@money4dentists.com or visit www.money4dentists.com. 